\title{
Comparative Study of Conventional and Organic Rice Cultivation System in Northeast China Based on LCA
}

\author{
Feng Zhe, Fan Qingxin* \\ School of Environment, Harbin Institute of Technology, Harbin, China \\ Email address: \\ fengz@hit.edu.cn (Feng Zhe), fanqingxin@hit.edu.cn (Fan Qingxin) \\ ${ }^{*}$ Corresponding author
}

\section{To cite this article:}

Feng Zhe, Fan Qingxin. Comparative Study of Conventional and Organic Rice Cultivation System in Northeast China Based on LCA. Science Discovery. Vol. 5, No. 3, 2017, pp. 186-191. doi: 10.11648/j.sd.20170503.15

Received: March 30, 2017; Accepted: April 24, 2017; Published: May 11, 2017

\begin{abstract}
With the method of life cycle assessment, the paper takes Bayan County, Heilongjiang Province as the case to analyze the resources' consumption and pollutant releasing of conventional and organic rice cultivation system in northeast China. On the basis of that, the comparative environmental assessment was accomplished. The results showed that the significant environmental impact factors are global warming potential, acidification potential, eutrophication potential and fresh water eco-toxicity potential. The environmental impact index of conventional rice is 5.24 in comparison with 4.15 for organic rice. If conventional rice were widely replaced by organic rice, acidification, eutrophication, human toxicity and fresh water eco-toxicity potential would be reduced by $47 \%, 32 \%, 85 \%$ and $67 \%$. However, global warming and fossil energy consumption potential would increase $65 \%$ and $14 \%$. In terms of environmental impact, organic rice is not totally superior to conventional rice. In the system of conventional rice cultivation, the agricultural materials period contributes most to environmental impact, occupying more than $60 \%$ in eutrophication, fresh water eco-toxicity, terra firma eco-toxicity, human toxicity, acidification and fossil energy consumption potential. In the system of organic rice cultivation, growing period contributes most to environmental impact, taking the place of the agricultural materials period. Thus, actualizing energy-saving and cleaner production in the fertilizer industry, promoting fair irrigation projects and optimizing fertilizer application are the key points to control the potential environmental impacts.
\end{abstract}

Keywords: Life Cycle Assessment, Conventional Rice, Organic Rice, Environmental Impacts

\section{基于LCA的常规水稻与有机水稻种植系统的环境影响对比研究}

\author{
冯喆, 樊庆锌* \\ 环境学院, 哈尔滨工业大学, 哈尔滨, 中国 \\ 邮箱 \\ fengz@hit. edu.cn（冯喆）, fanqingxin@hit. edu.cn（樊庆锌）
}

摘要：以中国黑龙江省巴彦县为例, 采用生命周期评价的方法, 研究了东北地区常规水稻与有机水稻种植系统的资源 消耗及环境释放, 在此基础上, 进行了生命周期环境影响评价。结果表明, 水稻种植的环境影响主要有全球变暖潜能、 酸化潜能、富营养化潜能和淡水生态毒性潜能。两种水稻的环境影响综合指数分别为 5.24 和 4.15 。若将有机水稻替代 常规水稻广泛种植，酸化、富营养化、人类毒性和淡水生态毒性潜能将会降低47\%、32\%、85\%和 $67 \%$ ，但全球变暖和化 石能源消耗潜能将增加 $65 \%$ 和 $14 \%$ 。因此, 从环境影响的角度看, 有机水稻并不能全面优于常规水稻。常规水稻种植系 统中, 农资阶段是环境影响最大的过程，其对富营养化、水生态毒性、陆地生态毒性、人类毒性、酸化和化石能源消 
耗潜能的贡献均超过 $60 \%$ 。而在有机水稻种植系统中, 种植阶段取代农资阶段, 成为环境影响最大的过程。因此, 化肥 工业实施清洁生产，稻田耕作过程合理灌溉、优化施肥方式，是控制潜在环境影响的关键。

关键词: 生命周期评价, 常规水稻, 有机水稻, 环境影响

\section{1. 引言}

中国东北地区拥有世界三大黑土带之一的东北平原 黑土带, 是我国条件最好的一熟制作物种植区和商品粮生 产基地 [1]。水稻是东北地区重点发展的高产稳产作物, 东北大米深受我国人民的喜爱 $[2]$ 。然而，水稻在种植过 程中, 往往伴随着无法忽视的环境影响。除了资源和能源 的消耗外, 水稻种植不仅会对土壤和水体造成污染, 还被 广泛认为是温室气体的主要排放源之一 [3]。因此, 分析 和识别水稻生产过程中的环境影响, 对于实现农业清洁生 产具有重要意义。

生命周期评价（LCA）是一种从全局视角出发的环境 管理工具, 可用于识别和量化产品在整个生命周期过程中 得资源、能源消耗和污染释放, 并对其影响进行评价。国 际上, 学者运用LCA对农产品或农田管理措施开展研究已 较为广泛 [4] [5] [8], 近年来, 中国不少学者也开始把LCA 方法引入农业领域 [6] [7]。但是, 针对我国东北地区水稻 种植系统中的资源消耗与污染释放的研究仍然缺乏, 对于 常规水稻和有机水稻在环境影响方面的对比分析更为鲜 见。本文采用LCA的方法, 比较研究东北地区常规水稻与 有机水稻种植系统的环境影响, 为东北地区水稻种植系统 全程管理提供决策依据。

\section{2. 材料与方法}

\section{1. 研究对象与数据来源}

本文的研究对象为黑龙江省巴彦县洼兴镇有机水稻 合作社, 年平均气温 $2.5^{\circ} \mathrm{C}$, 年平均日照 2600 小时, 年降 水 574 毫米, 年结冻期 145 天左右, 无霜期一般在 122 至 130 天之间。合作市水稻种植面积为 1333 公顷, 水稻年产量 1200 吨, 其中常规水稻亩产约为有机水稻的 1.82 倍。

本研究涉及的数据包括经实地调研得到的实景数据 和从统计年鉴、文献报道及大型数据库中获取的背景数据。 实景数据如下:

（1）浸种: 消毒液（3\%广枯灵）每公顷消耗 $1.5 \mathrm{~kg}$ 。

（2）翻耕：每公顷约消耗81L柴油。包括旋耕45L、 耙耕以及其他作业36L。

（3）插秩：每公顷约消耗13.5L柴油。

（4）灌溉：灌溉用水来自洼兴镇东部的江湾水库, 依靠地势自流。每公顷灌溉用水约 $1875 \mathrm{~m}^{3}$ 。

（5）化肥：普通水稻每公顷施尿素 $112.5 \mathrm{~kg}$ 、磷酸二 铵 $375 \mathrm{~kg}$ 、钾肥 $103.4 \mathrm{~kg}$ 。有机水稻每公顷施有机肥 $662.3 \mathrm{~kg}$ 。

（6）农药：每公顷施氯虫酰胺 $13.5 \mathrm{~kg}$ 、防病剂（多 菌灵、咪鲜胺 $1: 5$ 组合） $6.1 \mathrm{~kg}$ 。化肥农药均从洼兴镇购 买, 运输距离约 $14 \mathrm{~km}$, 化肥农药施加均为人工操作。
（7）退水: 依靠地势自流退水, 进入地下水体中。

（8）收割: 每公顷消耗28.4L柴油, 机械收割, 秸秆 粉碎全部还田。

（9）烘干: 每吨大米消耗1.43kg煤。煤与柴油从巴 彦镇购入, 运输距离 $37 \mathrm{~km}$ 。

\section{2. 生命周期评价}

\subsection{1. 目标与范围界定}

本研究的目标是量化水稻种植过程的环境影响, 找出 其中影响显著的环节。以年产量 1200 吨作为生命周期分析 的功能单元, 运用 $\mathrm{GaBi}$ 软件, 分别分析生产 1200 吨有机水 稻和 1200 吨常规水稻的生命周期内各环节所有能量或物 质的投入、产出所产生的环境影响。

本研究中系统边界定义为, 从与水稻生命周期有关的 矿石和能源开采开始, 到作物种植环节输出农产品终止, 包括原料阶段、农资阶段和作物种植阶段三个主要部分。 原料阶段主要考虑水稻种植所需的化肥生产所用原料 (矿 石）的开采与运输的环境影响; 农资阶段主要考虑化肥在 生产过程中的环境影响; 作物种植阶段则考虑包括播种、 插秧、灌溉、化肥农药的施用、收割及秥秆处理等作业活 动的环境影响。系统边界如图1。

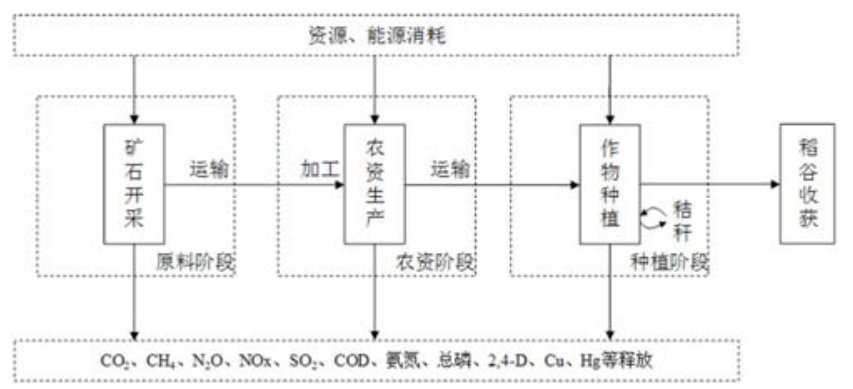

图1 水稻种植系统边界图。

\subsection{2. 清单分析}

清单分析是整个系统生命周期评价的基础, 是对产品 系统的整个生命周期过程中的原材料和能源的输入以及 环境释放等输出的客观量化过程。

水稻种植的原料和农资阶段主要考虑农药化肥生产, 包括所用原料 (矿产) 的开采产生的环境影响。由于影响 较小且数据获取难度较大, 相关的厂房设备、建筑设施和 农机工具生产的环境影响不予考虑。本研究中的化肥有尿 素、磷酸二铵、硫酸钾和有机肥。涉及到的原料开采过程 包括无烟煤、天然气、磷矿石、硫磺、硫铁矿和冶炼烟气 的开采及制备。

种植阶段主要能源消耗为翻耕、插种及收割阶段的机 械柴油及烘干阶段燃料煤的消耗, 资源消耗为灌溉用水及 化肥农药的投加。普通水稻与有机水稻在种植阶段的主要 
区别在于施肥种类, 普通水稻以尿素、磷酸二铵和硫酸钾 作为肥料, 有机水稻施加有机肥。所用有机肥以牛粪为原 料生产， N、P、K含量为 $5 \%$ 。

相关的资源能耗参数及污染物排放系数主要取自 GaBi Database、Ecoinvent和Agri Balyse数据库, 并结 合国内相关研究文献 [9-13]予以修正。

\subsection{3. 影响评价}

生命周期影响评价对产品或服务进行环境影响预测 的一步工作, 其实质上是对清单分析结果进行定性和定量 化研究。主要分为三个步骤: 特征化、标准化和加权评估。

(1) 特征化

经核算得到的清单当中, 并不能直观反映出人们关心 的环境问题。特征化的目的即是将清单数据以环境影响的 形式体现。本研究选取7种环境影响, 分别为化石燃料消 耗潜能ADPfossi1、全球变暖潜能GWP、酸化潜能AP、富营 养化潜能EP、人类毒性潜能HTP、淡水生态毒性潜能FAETP 和陆地生态毒性潜能TETP。本研究采用国际上通常的相关 性系数法进行计算。各环境影响类型的相关系数见表 1 。

本文对每一类环境影响潜能将采取公式（1）中的模 型进行计算:

$$
E P(j)=\sum E P(j)_{i}=\sum\left[Q_{i}(j) \times E F(j)_{i}\right]
$$

式中, $E P(j)$ 为产品系统对第 $j$ 中环境影响的特征化值; $E P(j) i$ 为第 $i$ 种排放物质对第 $j$ 中环境影响的特征化值; $E F(j)$ 为第 $i$ 种排放物质对第 $j$ 中环境影响的相关性系数; $Q_{i}$ 为第 $i$ 种物质的排放量。

表1 环境影响类型相关性系数。

\begin{tabular}{|c|c|c|c|c|c|}
\hline 环境影响 & 污染物 & 相关性系数 & 环境影响 & 污染物 & $\begin{array}{l}\text { 相关性 } \\
\text { 系数 }\end{array}$ \\
\hline \multirow{4}{*}{ ADPfossil } & 原油 & 41.87 & \multirow{6}{*}{$\mathrm{EP}$} & $\mathrm{PO}_{4}{ }^{3+}$ & 1 \\
\hline & 天然气 & 38.84 & & $\mathrm{P}$ & 3. 06 \\
\hline & 硬煤 & 27.91 & & $\mathrm{NO}_{\mathrm{x}}$ & 0.13 \\
\hline & 褐煤 & 13.96 & & $\mathrm{NH}_{4}^{3+}$ & 0.35 \\
\hline \multirow{3}{*}{ GWP } & $\mathrm{CO}_{2}$ & 1 & & COD & 0.022 \\
\hline & $\mathrm{CH}_{4}$ & 21 & & $\mathrm{~N}_{2} \mathrm{O}$ & 0.270 \\
\hline & $\mathrm{N}_{2} \mathrm{O}$ & 310 & \multirow{5}{*}{ HTP } & $\mathrm{C}_{6} \mathrm{H}_{4} \mathrm{Cl}_{2}$ & 1 \\
\hline \multirow{4}{*}{$\mathrm{AP}$} & $\mathrm{SO}_{2}$ & 1 & & $\mathrm{HF}$ & 3. $6 \times 10^{3}$ \\
\hline & $\mathrm{H}_{2} \mathrm{~S}$ & 1.88 & & $\mathrm{~V}^{3+}$ & $1.9 \times 10^{4}$ \\
\hline & $\mathrm{SO}_{3}$ & 0.8 & & $\mathrm{As}^{5+}$ & $3.5 \times 10^{5}$ \\
\hline & $\mathrm{NO}_{\mathrm{x}}$ & 0.7 & & $\mathrm{Ni}^{2+}$ & $3.5 \times 10^{4}$ \\
\hline \multirow{5}{*}{ FAETP } & $\mathrm{C}_{6} \mathrm{H}_{4} \mathrm{Cl}_{2}$ & $2.4 \times 10^{-3}$ & \multirow{5}{*}{ TETP } & $\mathrm{C}_{6} \mathrm{H}_{4} \mathrm{Cl}_{2}$ & 1 \\
\hline & Co & $6.0 \times 10^{2}$ & & $\mathrm{Be}$ & $3.6 \times 10^{3}$ \\
\hline & $\mathrm{Cu}^{2+}$ & 98 & & $\mathrm{Hg}^{2+}$ & $5.6 \times 10^{4}$ \\
\hline & $\mathrm{Ni}^{2+}$ & $2.0 \times 10^{2}$ & & $\mathrm{Ni}^{2+}$ & $2.4 \times 10^{2}$ \\
\hline & $\mathrm{Se}$ & $5.41 \times 10^{2}$ & & $\mathrm{As}^{5+}$ & 3. $3 \times 10^{3}$ \\
\hline
\end{tabular}

（2）标准化与加权评估

标准化过程主要是建立标准化基准, 各类环境影响经 标准化后可得出一个相对于总的环境影响的, 表征其影响 大小的无量纲的值, 使不同类型的环境影响之间可互相比 较。本文选取Sleeswijk [14] 等提出的全球人均环境影响 潜力作为标准化基准值, 并采用层次分析法与摘权法相结
合的方法, 对七种环境影响类型进行赋权。标准化因子及 权重见表2。

表2 七种环境影响类型标准化因子及权重。

\begin{tabular}{llll}
\hline 影响类型 & 标准化基准值 & 单位 & 权重 \\
\hline ADPfossi1 & 1282.35 & $\mathrm{MJ}$ & 0.0273 \\
GWP & 6889.73 & $\mathrm{kgCO}_{2}$ 当量 & 0.2643 \\
$\mathrm{AP}$ & 52.41 & $\mathrm{kgSO}_{2}$ 当量 & 0.0500 \\
EP & 0.62 & $\mathrm{kgPO}_{4}$ 当量 & 0.0698 \\
HTP & 1460.36 & $\mathrm{~kg} 1,4-\mathrm{DCB}$ 当量 & 0.3527 \\
FAETP & 5.06 & $\mathrm{~kg} 1,4-\mathrm{DCB}$ 当量 & 0.1379 \\
TETP & 8.39 & $\mathrm{~kg} 1,4-\mathrm{DCB}$ 当量 & 0.0980 \\
\hline
\end{tabular}

\section{3. 结果与分析}

\section{1 . 清单分析}

根据拟定的系统边界, 在 $\mathrm{GaBi}$ 软件中, 对系统中每项 进程进行建模和赋值, 建立普通水稻和有机水稻种植过程 模型如图2、图3所示。核算后, 得到普通水稻和有机水稻 种植系统资源消耗与污染是释放清单, 如表 3 和表 4 所示。

由表 8 和表 9 可知, 从资源消耗来看, 有机水稻种植系 统与常规水稻相差不大, 其中, 前者的硬煤消耗量更高, 为后者的 1.78 倍。除此之外, 各项资源消耗量均略低于常 规水稻, 消耗总量是后者的 0.81 倍。

污染释放方面, 有机水稻种植系统有 6 项指标高于常 规水稻, 分别为NMVOC、 $\mathrm{NH}_{3} 、 \mathrm{CH}_{4} 、 \mathrm{BOD} 、 \mathrm{COD}$ 和氨氮, 相同 产量下, 释放量分别为常规水稻的 1.81 倍、 1.04 倍、 2.13 倍、1.96倍、1.80倍和1.99倍。对于其他污染物指标, 常 规水稻种植的排放量均高于有机水稻。

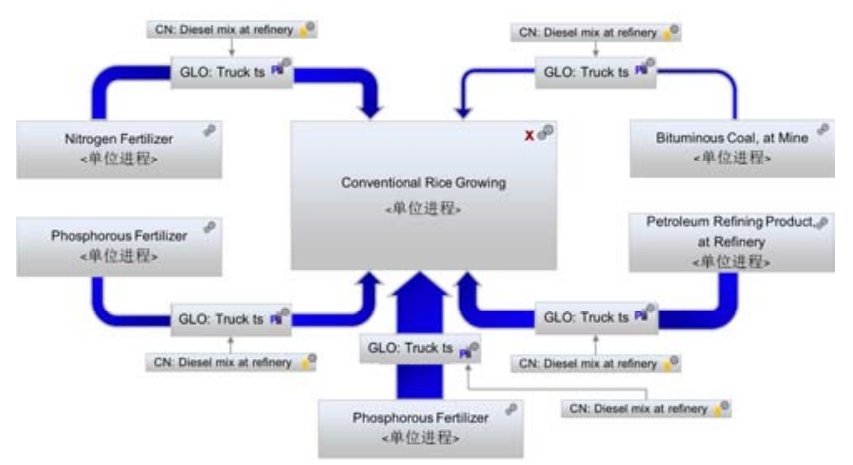

图2 普通水稻种植系统软件模型示意图。

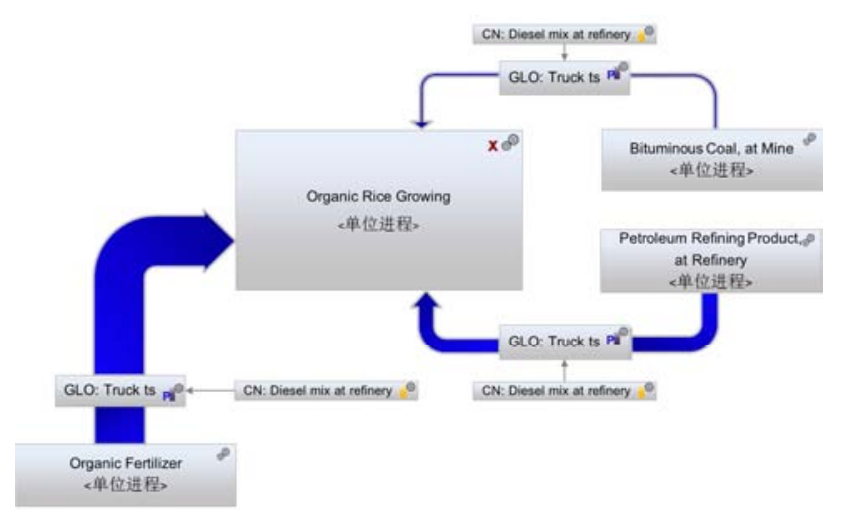

图3 有机水稻种植系统软件模型示意图。 
表3 水稻种植系统资源消耗清单 (单位: $\mathrm{kg}$ ) 。

\begin{tabular}{llll}
\hline 类别 & 物质/元素 & 普通水稻 & 有机水稻 \\
\hline & 原油 & 1879.73 & 1508.32 \\
& 硬煤 & 1536.56 & 2739.53 \\
& 褐煤 & 0.80 & 0.64 \\
& 天然气 & 124.04 & 99.53 \\
非可再生资源 & 惰性石 & 154.99 & 124.37 \\
& 钾盐 & 2.15 & 1.73 \\
& 天然骨料 & 1.82 & 1.46 \\
& 磷矿 & 0.35 & 0.28 \\
& 其他 & 3.62 & 2.91 \\
& 铁 & 1.81 & 1.45 \\
非可再生元素 & 铅 & 0.026 & 0.021 \\
& 锰 & 0.019 & 0.015 \\
& 锌 & 0.017 & 0.014 \\
& 铜 & 0.005 & 0.004 \\
& 其他 & 0.007 & 0.006 \\
可再生资源 & 水 & 134454.02 & 107887.76 \\
& 空气 & 896.19 & 719.12 \\
总计 & 二氧化碳 & 21.79 & 17.48 \\
& 其他 & 0.025 & 0.020 \\
& & 139087.65 & 113115.16 \\
\hline
\end{tabular}

表4 水稻种植系统污染释放清单 (单位: $\mathrm{kg}$ ) 。

\begin{tabular}{|c|c|c|c|}
\hline 类别 & 物质/元素 & 普通水稻 & 有机水稻 \\
\hline \multirow{6}{*}{ 大气污染物 } & $\mathrm{CO}_{2}$ & 85476.88 & 4780.76 \\
\hline & $\mathrm{SO}_{2}$ & 7928. 86 & 702.44 \\
\hline & $\mathrm{CO}$ & 10855.79 & 6420.89 \\
\hline & $\mathrm{N}_{2} \mathrm{O}$ & 1356.47 & 0.09 \\
\hline & NMVOC & 341.96 & 619. 47 \\
\hline & $\mathrm{NH}_{3}$ & 1782.07 & 1861.97 \\
\hline \multirow{12}{*}{ 水体污染物 } & $\mathrm{CH}_{4}$ & 53579.39 & 114361.84 \\
\hline & BOD & 5.57 & 10.91 \\
\hline & COD & 38.26 & 69.01 \\
\hline & 氨氮 & 2. 46 & 4.90 \\
\hline & 氯化物 & 411.90 & 330.514 \\
\hline & 硫化物 & 0.98 & 0.817 \\
\hline & 铬 & 22.60 & 0.183 \\
\hline & 砷 & 15. 01 & 0.008 \\
\hline & 铜 & 10.50 & 0.003 \\
\hline & 镍 & 7. 50 & 0.004 \\
\hline & 铅 & 7. 50 & 0.002 \\
\hline & 镉 & 5.00 & 0.003 \\
\hline
\end{tabular}

\section{2. 影响评价}

以清单分析的结果为基础, 经特征化、标准化和加权 评估, 得到常规水稻与有机水稻种植系统各环境影响类型 之间的对比情况如图4。

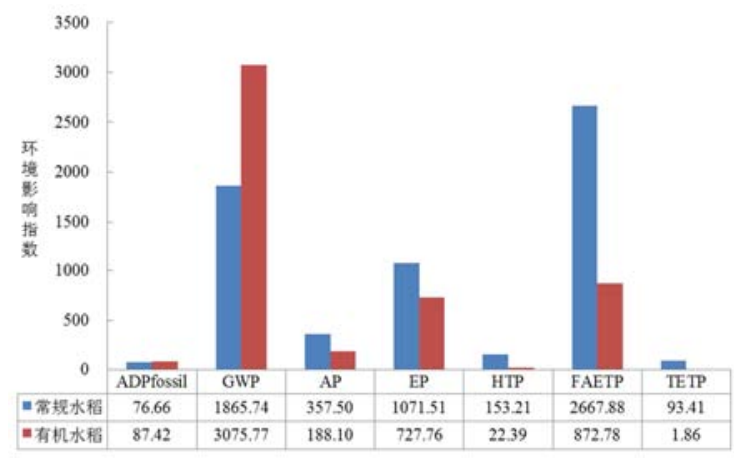

图4 常规水稻与有机水稻种植系统各环境影响类型对比图。
由图4可知, 在七种环境影响类型中，水稻种植系统 贡献较大的有全球变暖潜能、酸化潜能、富营养化潜能和 淡水生态毒性潜能。其中，有机水稻对全球变暖的贡献高 于常规水稻, 环境影响指数为 3075.77 , 折合成每吨为 2.56 , 即每生产 $1 \mathrm{t}$ 有机水稻的全球变暖潜能相当于全球人均贡 献的 2.56 倍, 为常规水稻种植系统的 1.65 倍。常规水稻对 淡水生态毒性潜能、富营养化潜能和酸化潜能的贡献高于 有机水稻, 环境影响指数分别为 $2267.88 、 1071.51$ 和 357.50 , 折合成每吨分别为 $2.22 、 0.89$ 和 0.30 , 分别为有 机水稻的 3.06 倍、 1.47 倍和 1.90 倍。折合成每吨后, 两种 水稻的环境影响综合指数分别为 5.24 和 4.15 。

图5表示了常规水稻种植系统的各个阶段对不同环境 影响类型的贡献度对比情况。

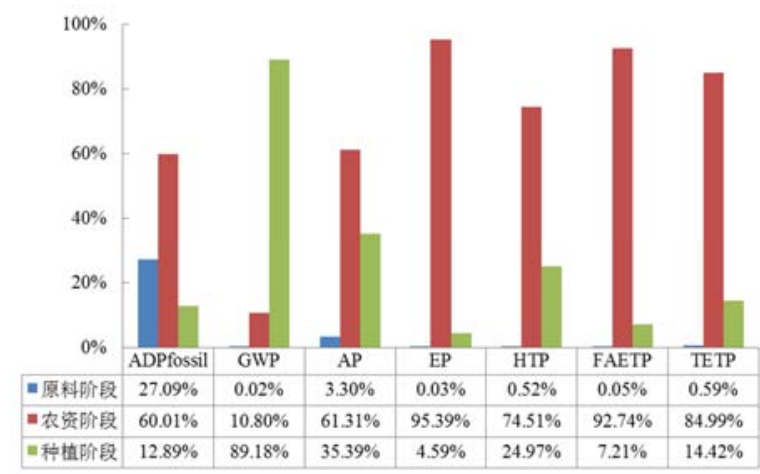

图5 常规水稻种植系统各阶段的环境影响贡献。

由5可知, 原料阶段除在化石能源消耗潜力中占 $27.09 \%$ 外, 在其余6种环境影响类型中贡献均低于 $5 \%$ 。种植阶段 贡献最大的环境影响类型为全球变暖潜力, 占 $89.18 \%$, 对 于酸化潜力、人类毒性潜力、陆地生态毒性潜力和化石能 源消耗潜力的贡献分别为 $35.39 \% 、 24.97 \% 、 14.42 \%$ 和 $12.89 \%$ 。农资阶段对多个环境影响类型中贡献巨大, 其在 富营养化潜力、水生态毒性潜力、陆地生态毒性潜力、人 类毒性潜力、酸化潜力和化石能源消耗潜力中均为三个阶 段里贡献最大的，占比分别为 $95.39 \% 、 92.74 \% 、 84.99 \%$ 、 $74.51 \% 、 61.31 \%$ 和 $60.01 \%$ 。

图6表示了有机水稻种植系统的各个阶段对不同环境 影响类型的贡献度对比情况。由图可知, 原料阶段在化石 能源消耗潜力和陆地生态毒性潜力中贡献最高, 分别占 43. $24 \%$ 和 $53.53 \%$ 。此外, 原料阶段还在淡水生态毒性潜力 中贡献了 $42.31 \%$ 。有机水稻种植系统的农资阶段的环境影 响贡献明显低于普通水稻, 在各项环境影响类型中贡献均 低于 $50 \%$, 仅在淡水生态毒性潜力中贡献最高, 占 $46.25 \%$ 。 种植阶段成为有机水稻种植系统中贡献最大的过程, 其在 全球变暖潜力中几乎占据全部比重, 比例高达 $99.81 \%$, 对 于人类毒性潜力、富营养化潜力和酸化潜力的贡献同样最 大, 占比分别为 $53.52 \% 、 52.70 \%$ 和 $46.96 \%$ 。

\section{3. 生命周期解释}

\section{3. 1 . 全球变暖潜能}

常规水稻的全球变暖潜能主要发生在种植阶段和农 资阶段。种植阶段产生的稻田温室气体 $\mathrm{CH}_{4}$ 和 $\mathrm{N}_{2} \mathrm{O}$ 是水稻种 
植系统碳排放的最主要原因, 农资阶段主要来源于化肥生 产所产生的 $\mathrm{CO}_{2}$ 。有机水稻的全球变暖潜能主要发生在种 植阶段, 其主要来源也是稻田温室气体的排放, 由于有机 水稻亩产量较低, 相同产量下, 其对全球变暖的贡献高于 常规水稻, 为常规水稻种植系统的 1.65 倍。

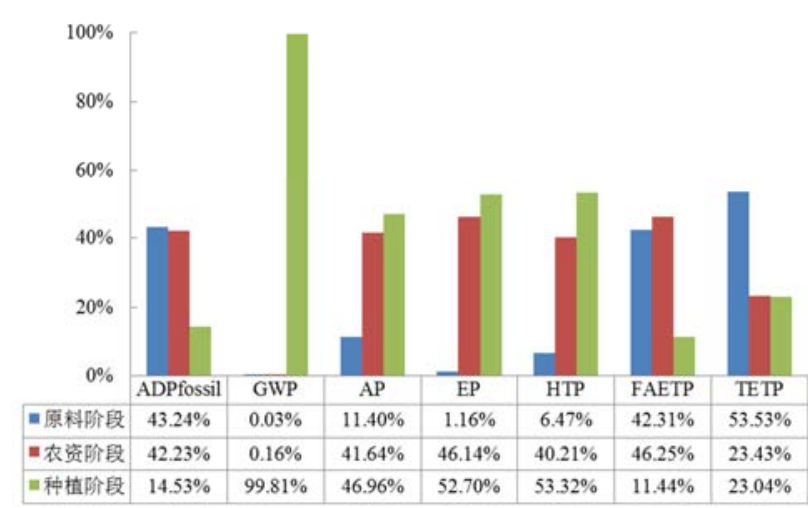

图6 有机水稻种植系统各阶段的环境影响贡献。

研究表明, 灌溉模式、施肥品种及施肥量是稻田 $\mathrm{CH}_{4}$ 排放的主要影响因素。通过干湿交替灌溉, 增加土壤通气 性可以显著减少稻田 $\mathrm{CH}_{4}$ 的排放 [15]。土壤中肥料在厌氧 状态下, 经反硝化菌的作用释放出 $\mathrm{N}_{2} \mathrm{O}$ 。因此, 开展测土 配方优化施肥量, 将会有效降低肥料生产所产生的 $\mathrm{CO}_{2}$ 和 肥料经反硝化产生的 $\mathrm{N}_{2} \mathrm{O}$ 。

\section{3.2. 酸化潜能}

酸化潜能主要发生在农资阶段和种植阶段。农资阶段 肥料生产所产生的 $\mathrm{SO}_{\mathrm{x}}$ 和 $\mathrm{NO}_{\mathrm{x}}$ 是环境酸化的主要原因, 种植 阶段主要来源于肥料中氮素水解产物 $\mathrm{NH}_{4}{ }^{+}$的硝化反应和 $\mathrm{NO}_{3}{ }^{-}$的淋溶作用 $[16]$ 。由于尿素、磷酸二铵和硫酸钾的生 产过程涉及到合成氨、磷酸和硫酸的制备 [9]，伴随的 $\mathrm{S}_{\mathrm{x}}$ 和 $\mathrm{NO}_{\mathrm{x}}$ 的产生量远大于有机肥的生产过程, 因此常规水稻 对酸化潜能的贡献高于有机水稻, 为有机水稻种植系统的 1.90倍。

研究表明, 水寒轮作模式下稻田酸化速率是持续种稻 模式的10倍, 而持续种稻的稻田酸化情况不显著 [17]。我 国东北地区稻田多采用持续种稻模式, 因此, 优化施肥量 仍是控制水稻田酸化的有效手段。

\section{3. 3. 富营养化潜能}

水稻的富营养化潜能主要发生在农资阶段和种植阶 段。农资阶段主要由于肥料生产所产生的 $\mathrm{PO}_{4}{ }^{3+} 、 \mathrm{NH}_{4}{ }^{3+}$ 和 $\mathrm{NO}_{\mathrm{x}}$, 种植阶段农田氮磷流失是引起富营养化的重要原因。与酸 化潜能类似, 常规水稻农资阶段化肥的生产过程中涉及合 成氨、磷酸和硫酸的制备, $\mathrm{PO}_{4}{ }^{3+} 、 \mathrm{NH}_{4}{ }^{3+}$ 和 $\mathrm{NO}_{\mathrm{x}}$ 的产生量大于 有机肥的生产过程, 因此常规水稻对富营养化潜能的贡献 高于有机水稻, 为有机水稻种植系统的 1.47 倍。

控制氮磷养分径流流失的主要手段有田间管理和肥 料控制等。田间管理方面, 与其他耕作方式相比, 免耕可 有效降低 $\mathrm{NO}_{3}{ }^{-}$的淋溶, 地表径流量是犁耕农田的54\% [18]; 延迟耕作时间有助于延缓土壤中作物残渣的矿化, 进而减 弱 $\mathrm{NO}_{3}{ }^{-}$的淋溶的径流 [19]; 此外, 节水灌溉可优化稻田表
层的物化特征, 进而降低氮磷的径流流失率 [20]。肥料控 制方面, 有研究 [21]认为, 滴灌施肥的方式, 可以在基本 保持作物产量的前提下, 较为明显地削减氮磷的径流流失。

\section{3. 4. 淡水生态毒性潜能}

常规水稻的淡水生态毒性潜能主要发生在农资阶段, 磷肥和钾肥的生产过程涉及冶炼烟气的制备, 伴随的含重 金属废弃物是淡水生态毒性的最主要来源, 而有机肥在生 产过程中无需制备治炼烟气, 因此常规水稻的淡水生态毒 性潜能远高于有机水稻, 为有机水稻种植系统的 3.06倍。 相比之下, 种植阶段对淡水生态毒性潜能的贡献较小, 但 考虑到实际田间作业过程中, 高毒高残留农药往往被普遍 使用，仍具有不容小觑的生态毒性 [22]。

\section{4. 结论与展望}

通过研究, 本文得到以下结论:

(1) 水稻种植的环境影响类型主要有全球变暖潜能、 酸化潜能、富营养化潜能和淡水生态毒性潜能。常规水稻 种植系统中, 农资阶段是对环境影响贡献最大的过程, 其 对富营养化、水生态毒性、陆地生态毒性、人类毒性、酸 化和化石能源消耗潜能的贡献均超过 $60 \%$ 。而在有机水稻 种植系统中, 种植阶段取代农资阶段, 成为环境影响贡献 最大的过程。因此, 化肥工业实施清洁生产, 稻田耕作过 程合理灌溉、优化施肥方式, 是控制潜在环境影响的关键。

(2) 综合比较生产 $1 \mathrm{t}$ 常规水稻和有机水稻, 二者的 环境影响综合指数分别为 5.24 和 4.15 。若将常规水稻换成 有机水稻广泛种植, 酸化、富营养化、人类毒性和淡水生 态毒性潜能将会降低47\%、32\%、85\%和 $67 \%$, 但全球变暖和 化石能源消耗潜能将增加 $65 \%$ 和 $14 \%$ 。因此, 从环境影响的 角度看, 有机水稻并不能全面优于常规水稻。

本文对水稻种植系统环境影响方面的研究进行了有 益的探索, 采用LCA的方法, 比较研究了东北地区常规水 稻与有机水稻种植系统的资源消耗及环境释放, 为东北地 区水稻种植系统全程管理提供决策依据。

\section{参考文献}

[1] 丁栋. 我国发布种植业结构调整5年规划 $[J]$. 农业机械, 2016, 5:002。

[2] 孙强, 张三元, 张俊国, 等. 东北水稻生产现状及对策 $[\mathrm{J}]$. 北 方水稻, 2010, $40(2): 72-74$ 。

[3] Tilman, D., Fargione, J., Wolff, B., D’ Antonio, C., Dobson, A., Howarth, R., Schindler, D., Schlesinger, W. H., Simberloff, D., Swackhamer, D., 2001. Forecasting agriculturallydriven global environmental change. Science 292, $281-284$.

[4] Blengini G. A, Busto M. The life cycle of rice: LCA of alternative agri-food chain management systems in Vercelli (Italy)[J]. Journal of environmental management, 2009, 90(3): 1512-1522. 
[5] Brentrup F, Küsters J, Kuhlmann H, et al. Environmental impact assessment of agricultural production systems using the life cycle assessment methodology: I. Theoretical concept of a LCA method tailored to crop production[J]. European Journal of Agronomy, 2004, 20 (3) : 247-264.

［6］王明新，包永红，吴文良，等. 华北平原冬小麦生命周期 环境影响评价 $[\mathrm{J}]$. 农业环境科学学报, 2006, 25(5):1127-1132。

[7] 梁龙，陈源泉，高旺盛，等. 华北平原冬小麦-夏玉米种植 系统生命周期环境影响评价 $[\mathrm{J}]$. 农业环境科学学报, 2009, 28 (8) : 1773-1776。

[8] IS0 E. N. 14040: 2006[J]. Environmental management-Life cycle assessment-Principles and framework. European Committee for Standardization, 2006.

[9］王利. 中国化肥产业体系养分资源流动规律与管理策略研 究 [D]. 华中农业大学, 2008。

[10] 朱兆良. 农田中氮肥的损失与对策 $[\mathrm{J}]$. 土壤与环境, 2000, 9 (1) : 1-6。

[11］邱卫国, 唐浩, 王超. 水稻田面水氮素动态径流流失特性 及控制技术研究 [J] . 农业环境科学学报, 2004, 23 (4) :740-744。

[12] 周静雯, 苏保林, 黄宁波, 等. 不同灌溉模式下水稻田径 流污染试验研究 $[J]$. 环境科学, 2016 (3) :963-969。

[13] 王开峰, 彭娜, 王屺荣, 等. 长期施用有机肥对稻田土壤 重金属含量及其有效性的影响 [J]. 水土保持学报, 2008, 22 (1) : 105-108。

[14] Sleeswijk A. W, van Oers L F. C. M, Guinée J. B, et al. Normalisation in product life cycle assessment:
An LCA of the global and European economic systems in the year $2000[\mathrm{~J}]$. Science of the total environment, 2008, 390 (1) : 227-240.

[15] 曹黎明, 李茂柏, 王新其, 等. 基于生命周期评价的上海 市水稻生产的碳足迹 [J]. 生态学报, 2014, 34 (2) : 491-499。

[16] Ju X. T, Xing G. X, Chen X. P, et al. Reducing environmental risk by improving $\mathrm{N}$ management in intensive Chinese agricultural systems[J]. Proceedings of the National Academy of Sciences, 2009, 106 (9) : 3041-3046.

[17] 周晓阳, 徐明岗, 周世伟, Colinet Gilles. 长期施肥下 我国南方典型农田土壤的酸化特征 $[J]$. 植物营养与肥料学 报，2015，(06):1615-1621。

[18] Tapia-Vargas M, Tiscareño-López M, Stone J. J, et al. Tillage system effects on runoff and sediment yield in hillslope agriculture[J]. Field Crops Research, 2001, 69(2): 173-182.

[19] Mitchell R. D. J, Harrison R, Russell K. J, et al. The effect of crop residue incorporation date on soil inorganic nitrogen, nitrate leaching and nitrogen mineralization[J]. Biology and fertility of soils, 2000, $32(4)$ : 294-301.

[20］夏小江. 太湖地区稻田氮磷养分径流流失及控制技术研究 [D]. 南京农业大学, 2012。

[21] 郭春霞, 沈根祥, 黄丽华, 等. 精确滴灌施肥技术对大棚 土壤盐渍化和氮磷流失控制的研究 $[\mathrm{J}]$. 农业环境科学学报, 2009, 28 (2) : 287-291。

[22] 梁龙, 陈源泉, 高旺盛. 两种水稻生产方式的生命周期环 境影响评价 [J].农业环境科学学报, 2009, (09) : 1992-1996。 